\title{
Effects of chronic forced-swim stress on behavioral properties in rats with neonatal repeated MK-801 treatment
}

\author{
Kouichi Kawabe
}

\begin{tabular}{|c|c|}
\hline Citation & Pharmacology Biochemistry and Behavior, 159: 48-54 \\
\hline Issue Date & $2017-08$ \\
\hline Type & Journal Article \\
\hline Textversion & author \\
\hline Right & $\begin{array}{l}\text { (C) } 2017 \text { Elsevier Inc. This manuscript version is made available under the } \\
\text { CC-BY-NC-ND } 4.0 \text { license. https://creativecommons.org/licenses/by-nc-nd/4.0/. } \\
\text { This is the accept manuscript version. The published version is available online at: } \\
\text { http://doi.org/10.1016/j.pbb.2017.06.009 }\end{array}$ \\
\hline DOI & 10.1016/j.pbb.2017.06.009 \\
\hline
\end{tabular}

\author{
Self-Archiving by Author(s) \\ Placed on: Osaka City University
}

KAWABE, K. (2017). Effects of chronic forced-swim stress on behavioral properties in rats with neonatal repeated MK-801 treatment. Pharmacology, Biochemistry and Behavior. 159, 48-54. https://doi.org/10.1016/j.pbb.2017.06.009 
Highlights

Stress-vulnerability in rats neonatallty treated with MK-801 was examined.

Rats were subjected to chronic forced-swim stress.

Neonatal MK-801 treatment reduced stress-induced immobility in the forced-swim test.

Neonatal MK-801 treatment may impair adaptation or coping ability against stress.

Discussing the results in terms of the two-hit hypothesis of schizophrenia. 
Effects of chronic forced-swim stress on behavioral properties in rats with neonatal repeated MK-801 treatment

Kouichi KAWABE ${ }^{\text {a,* }}$

${ }^{a}$ Graduate School of Literature and Human Sciences, Osaka City University, 3-3-138 Sugimoto, Sumiyoshi-ku, Osaka 558-8585, Japan

* Correspondence to:

K. Kawabe, Ph. D.

Graduate School of Literature and Human Sciences, Osaka City University

3-3-138 Sugimoto, Sumiyoshi-ku, Osaka 558-8585, Japan

Telefax: +81-6-6605-2380

E-mail: kawabe@lit.osaka-cu.ac.jp 
1 Abstract

2

The two-hit hypothesis has been used to explain the onset mechanism of 4 schizophrenia. It assumes that predisposition to schizophrenia is originally attributed to 5 vulnerability in the brain which stems from genetic or early developmental factors, and 6 that onset is triggered by exposure to later detrimental factors such as stress in 7 adolescence or adulthood. Based on this hypothesis, the present study examined 8 whether rats that had received neonatal repeated treatment with an $N$-methyl-D-aspartate 9 (NMDA) receptor antagonist (MK-801), an animal model of schizophrenia, were 10 vulnerable to chronic stress. Rats were treated with MK-801 $(0.2 \mathrm{mg} / \mathrm{kg})$ or saline twice 11 daily on postnatal days 7-20, and animals in the stress subgroups were subjected to 20 12 days (5 days/week $\times 4$ weeks) of forced-swim stress in adulthood. Following this, 13 behavioral tests (prepulse inhibition, spontaneous alternation, open-field, and forced14 swim tests) were carried out. The results indicate that neonatal repeated MK-801 15 treatment in rats inhibits an increase in immobility in the forced-swim test after they 16 have experienced chronic forced-swim stress. This suggests that rats that have 17 undergone chronic neonatal repeated NMDA receptor blockade could have a reduced ability to habituate or adapt to a stressful situation, and supports the hypothesis that these rats are sensitive or vulnerable to stress. 
22 Key words: NMDA receptors; Neonatal treatment; Animal model of schizophrenia;

23 Prepulse inhibition; Stress coping; Working memory; Open-field; Rats

24

25 Abbreviations: ANOVA, analysis of variance; DNMTP, delayed nonmatching-to26 position; HPA, hypothalamic-pituitary-adrenal; NMDA, $N$-methyl-D-aspartate; PCP, 27 phencyclidine; PND, postnatal day; PPI, prepulse inhibition; SA, spontaneous 28 alternation; SAL, saline. 
$N$-methyl-D-aspartate (NMDA) receptors, a subtype of ionotropic glutamate receptors, have been implicated in many neural processes. Therefore, treatment with NMDA antagonists impairs numerous neural and mental functions. For example, many studies have shown that NMDA receptors are involved in long-term potentiation, which is believed to be one of the physiological bases for learning and/or memory (Abraham and Mason, 1988; Harris et al., 1984; Morris, 1989; Morris et al., 1986; Morris et al., 1989), and that NMDA receptor antagonists induce learning and/or memory impairments (Kawabe et al., 1998a; Kawabe et al., 1998b; Morris, 1989; Morris et al., 1986; Morris et al., 1989; Yoshihara and Ichitani, 2004). Furthermore, it is also well known that NMDA receptor antagonists such as phencyclidine (PCP) and ketamine induce positive and negative schizophrenia-like symptoms in humans and animals (Bubeníková-Valešová et al., 2008; Javitt and Zukin, 1991).

In addition to these findings based mainly on treatment with NMDA receptor antagonists in adulthood, it is also frequently reported that repeated treatment with antagonists such as PCP and MK-801 (dizocilpine; 5-methyl-10,11-dihydro-5Hdibenzo[a,d]-cyclohepten-5,10-imine) during the early developmental stage can cause long-term alterations of anatomical, neurochemical, neurophysiological, behavioral, and other parameters in rats and mice (for example, Facchinetti et al., 1993; Facchinetti et al., 1994; Gorter et al., 1992a; Gorter and de Bruin, 1992; Gorter et al., 1991; Gorter et al., 1992b; Kawabe et al., 2007; Kawabe and Miyamoto, 2008; Nakatani-Pawlak et al., 2009; Niikura et al., 2015; Sircar, 2003; Stefani and Moghaddam, 2005; Wang et al., 2003). Additionally, since blockade of NMDA receptors in early developmental stages 
induces neural degeneration, and impairs normal development of the neural circuits and the brain (Beninger et al., 2002; Facchinetti et al., 1993; Facchinetti et al., 1994; Ikonomidou et al., 1999; Kawabe and Miyamoto, 2008; Nakatani-Pawlak et al., 2009; O'Donoghue et al., 1993; Wang et al., 2004; Wang et al., 2003), rats or mice that have received this treatment are used as animal models which adhere to the neurodevelopmental hypothesis of schizophrenia. This hypothesis assumes that maldevelopment of the brain, which is caused by genetic defects, viral infection, obstetric problems and other detrimental factors in early developmental stages, contributes to the onset of schizophrenia (Lewis and Levitt, 2002; Weinberger, 1987). Our previous studies showed that neonatal repeated treatment with competitive (CGS 19755; cis-4-phosphonomethyl-2-piperadine carboxylic acid) and noncompetitive (MK801) NMDA receptor antagonists impaired spatial working memory in the radial-arm maze or the delayed nonmatching-to-position (DNMTP) tasks (Kawabe et al., 2007; Kawabe and Miyamoto, 2008). Since working memory is severely impaired in schizophrenic patients (Goldman-Rakic, 1994; Manoach, 2003), these results validate the use of animals with neonatal NMDA receptor blockade as a preclinical model of schizophrenia.

In addition to genetic and early developmental factors, stress is one of the risk factors associated with a variety of mental disorders. The two-hit hypothesis of schizophrenia assumes that genetic or early developmental defects (first hit) are potential factors in the onset of schizophrenia, and that later detrimental factors in adolescence or adulthood (second hit) trigger this onset (Bayer et al., 1999; Feigenson et al., 2014; Maynard et al., 2001). Since stress is considered to be a major second hit factor, it is valuable to examine whether animal models of schizophrenia are vulnerable 
to stress. The present study examined whether rats subjected to neonatal repeated treatment with an NMDA receptor antagonist (MK-801), an animal model of schizophrenia, had stress-vulnerability as assessed by several behavioral or cognitive measures; sensorimotor gating, working memory, locomotor activity, and stress coping. These behavioral parameters were tested after chronic forced-swim stress had been applied in adulthood. Forced-swim stress is commonly used in stress studies of rats and mice, and it has been frequently reported to induce stress-related endocrinal, neural, and behavioral alterations (for example, Anisman et al., 2001; de Kloet and Molendijk, 2016; Shishkina et al., 2015). Thus, I considered that it would be an effective second hit factor in the context of the two-hit hypothesis.

\section{Materials and methods}

\subsection{Animals}

Eight nests of Wistar rats, each of which had a foster mother, and four male and three female pups, were raised in individual plastic cages. The pups in each nest were originally borne by two to four different mothers, and were randomly assigned to the nest after birth; however, all of them were born on the same day. Only male pups were subjected to drug treatment with MK-801 or saline (SAL). Thus, 32 pups received drug treatment and were prepared for behavioral testing. On postnatal days (PNDs) 7-20 (the day of birth was defined as PND 0), animals were injected subcutaneously with (+)MK-801 hydrogen maleate (Sigma-Aldrich, St. Louis, Missouri, USA; $0.2 \mathrm{mg} / \mathrm{kg}$ ) dissolved in SAL, or an equal volume of SAL (1 ml/ $\mathrm{kg})$ twice daily. Each animal was 
assigned to one of the two drug groups so that the mean pretreatment body weight of the groups was almost equal. An interval of more than $8 \mathrm{~h}$ was interposed between each drug treatment. The animals were weaned at PND 28, and thereafter housed individually in stainless steel wire cages with food and water ad libitum. Throughout the experimental period, subjects were maintained on a 12:12 h light-dark cycle. This study was conducted in accordance with the National Institutes of Health Guide for the Care and Use of Laboratory Animals, and approved by the committee for animal research in Osaka City University.

\subsection{Apparatus}

For the prepulse inhibition test, an acoustic startle apparatus (BTI 1000, BioMedica Ltd., Osaka, Japan) was used. It contained an animal holder placed in a soundattenuated chamber $(52 \mathrm{~cm}$ wide $\times 38 \mathrm{~cm}$ long $\times 37 \mathrm{~cm}$ high inside dimensions $)$ which had a ventilation fan and a small light bulb on an inner sidewall. The holder was made of semitransparent polyvinyl chloride, and consisted of a cylinder $(11 \mathrm{~cm}$ in diameter, $25 \mathrm{~cm}$ long) attached to a square platform $(20 \mathrm{~cm}$ wide $\times 30 \mathrm{~cm}$ long $)$. Each corner of the platform was unsteadily supported by polyurethane ball $(4 \mathrm{~cm}$ in diameter) placed on a short acrylic pipe $(3.5 \mathrm{~cm}$ in diameter, $5 \mathrm{~cm}$ long). Vibrations derived from the rat's startle responses in the cylinder were detected by a piezoelectric acceleration sensor below the platform. The detected responses were acquired by a data recording system (PowerLab 2/26; ADInstruments, Bella Vista, New South Wales, Australia), and converted to numeric data by data-processing software (LabChart; ADInstruments) running on a Microsoft Windows-based computer. Three speakers that were used to produce white noise were horizontally placed on the ceiling of the chamber so that they 
were above the cylinder. Each of the speakers separately produced continuous background noise, and prepulse and pulse stimuli. Illumination inside the apparatus was approximately $20 \mathrm{~lx}$. The volume of background noise, prepulses, and pulses was adjusted to 70,75 and $105 \mathrm{~dB}$, respectively.

A $\Psi$-shaped three-way maze made of gray polyvinyl chloride was used in the spontaneous alternation experiment. This maze consisted of a stem $(12 \mathrm{~cm}$ wide $\times 50$ $\mathrm{cm}$ long), three goal boxes (12 $\mathrm{cm}$ wide $\times 50 \mathrm{~cm}$ long for each), and a roughly hexagonal choice area $(31 \mathrm{~cm}$ wide at its widest point, and $19 \mathrm{~cm}$ long at its longest point) between the stem and the three goal boxes. The closed end of the stem included a start box (12 cm wide $\times 15 \mathrm{~cm}$ long). The central goal box was directly connected with the stem via the choice area. Each of the left and right goal boxes extended from the root of the central goal box at an angle of approximately 45 degrees. The central goal box was always closed by a guillotine door, and was not used in the experiment. The guillotine doors of the other goal boxes and that of the start box were always removed. The left and right goal boxes and the stem were used to assess the choice of the rat in the experiment. The illumination of the choice point was approximately $360 \mathrm{~lx}$.

A gray square box $(90 \times 90 \mathrm{~cm}, 30 \mathrm{~cm}$ in height $)$ was used as an open field. It was made of polyvinyl chloride, and had walls and a floor. The floor was divided into 25 (5 $\times 5)$ sections, each of which was $18 \times 18 \mathrm{~cm}$. A white bulb was suspended over the center of the apparatus, and the illumination of the center of the floor was approximately $300 \mathrm{~lx}$.

A transparent acrylic cylinder pool $(20 \mathrm{~cm}$ in diameter, $49 \mathrm{~cm}$ in depth) was used for the forced swim. It was filled with water $\left(25 \pm 1{ }^{\circ} \mathrm{C}\right)$, to a depth of $30 \mathrm{~cm}$. The behavior of the rat was observed from the side of the pool via a web camera. The 
immobility of the rat in the pool was measured by video-tracking software (ANY-maze; Stoelting Co., Wood Dale, Illinois, USA) running on a Microsoft Windows-based computer. In order to obtain a good contrast between the background and the rat, several drops of black ink were put into the water.

\subsection{Procedures}

Each of the drug groups within each nest consisted of two rats, and they were subdivided into two subgroups; no stress or stress. Thus, four rats within each nest were assigned to one of four experimental groups: SAL-no stress, SAL-stress, MK-801-no stress, and MK-801-stress. Since one rat treated with MK-801 died during the drug treatment period, the number of rats in the MK-801-no stress group was seven, while there were eight rats in the other three groups.

Rats in the stress subgroups were subjected to 20 days of a forced-swim stress session (5 days/week $\times 4$ weeks) from PND 56. During this period, rats were individually put into the water-filled forced-swim pool for 15 minutes daily.

From the day after the stress session had finished (PND 82), behavioral testing began. This consisted of prepulse inhibition (PPI), spontaneous alternation (SA), openfield, and forced-swim tests. These tests were conducted in the following order: PPI (days 1-3); SA and open field (day 4); forced swim (day 5).

\subsubsection{PPI}

The PPI test was conducted to measure sensorimotor gating in rats. On days 1 and 2, rats underwent a baseline session immediately following habituation. In habituation, a rat was placed in the cylinder for 10 min with background noise on. The baseline 
session was conducted to stabilize startle responses. This session had 40 pulse-alone trials, in each of which a 40-ms pulse stimulus was presented. An interval of $25 \mathrm{~s}$ on average (ranging from 15 to $35 \mathrm{~s}$ ) separated each trial.

On day 3, each rat was subjected to 5 min habituation followed by a 10-trial baseline session. Immediately after this, each rat received a test session. In this session, 20 pulse-alone trials and 20 prepulse trials were given in a pseudorandom order with the exception being that fewer than five trials of the same type occurred consecutively. A prepulse trial had a $20-\mathrm{ms}$ prepulse stimulus presented $100 \mathrm{~ms}$ before the beginning of a pulse stimulus. Pulse-alone trials were identical to those in the baseline session. An interval of $25 \mathrm{~s}$ on average (ranging from 15 to $35 \mathrm{~s}$ ) was interposed between each trial. Continuous background noise was presented throughout all the sessions on days 1-3.

In all of the pulse-alone and prepulse trials of the test session, 100 startle amplitudes were sampled every $1 \mathrm{~ms}$ immediately after onset of the pulse stimulus, and the startle response within each trial was defined as a summation of these 100 sampling values.

A mean value for the startle response was calculated for the pulse-alone trials and for the prepulse trials for each rat. Based on these means, a PPI score was calculated using the following formula, as the percentage inhibition by the prepulse stimuli on startle responses evoked by the pulses: \% PPI $=[1-$ (mean startle response in the prepulse trials) / (mean startle response in the pulse-alone trials) $] \times 100$.

\subsubsection{SA}

The rat was placed on the choice area of the maze, and allowed to freely explore the maze for $10 \mathrm{~min}$. The three arms of the maze were provisionally designated arms A, 
$\mathrm{B}$, and $\mathrm{C}$.

When all paws of the rat entered an arm, this arm was recorded as being entered. An SA was counted if three consecutive arm entries were different from each other. Percentage SAs, an index of working memory, was calculated by the following formula: $\% \mathrm{SAs}=[($ the number of SAs $) /($ total entries -2$)] \times 100$. For instance, if the rat entered the arms as follows: A B C B C A C B A C A, the number of SAs was counted as five (that is, "ABC","BCA", "ACB","CBA","BAC” in order), so percentage SAs was $[5 /(11-2)] \times 100=55.6 \%$. If a repeat entry to one arm (for example, reentry into arm A immediately after a choice to A) was observed, it was not considered a choice. An animal in the MK-801-stress group that had only three choices was excluded from the data analysis of $\%$ SAs.

freely. The numbers of traversed sections and rearings were counted for five min. identical to the forced-swim stress procedure, except that only one trial was conducted. in the last five min was measured.

\subsubsection{Statistical analysis}


of variance (ANOVAs). Percentages of SAs were transformed by an arcsine 223 transformation to modify heterogeneity of variance prior to the ANOVA. If an 224 interaction was revealed by an ANOVA, simple main effects were examined. Additionally, in the PPI test, the difference in startle responses between trial patterns (pulse-only vs. prepulse) was verified by a paired $t$-test in each of the four groups.

3. Results

\subsection{PPI}

PPI scores are shown in Fig. 1. The mean startle response in pulse-alone (panel A) and prepulse (panel B) trials are shown in Fig. 2. For all of these measures no significant differences were seen between experimental groups, although significant inhibitory effects of prepulse stimuli on startle responses were observed in all four groups [SAL-no stress: $t(7)=3.57, p<.01$; SAL-stress: $t(7)=3.44, p<.05$; MK-801no stress: $t(6)=3.12, p<.05 ; \mathrm{MK}-801-$ stress: $t(7)=5.31, p<.01]$.

\subsection{SA}

The mean percentage of SAs (panel A), and the mean number of total choices (panel B) are shown in Fig. 3. No significant differences in \% SAs were seen between groups. There was a trend toward a decrease in total choices following MK-801 treatment $[F(1,27)=3.25, p=.083]$.

\subsection{Open field}


The mean values of the numbers of sections traversed (panel A) and rearings

247 (panel B) are shown in Fig. 4. Chronic stress significantly increased rearing activity $248[F(1,27)=4.48, p<.05]$. On the other hand, there was a trend toward a decrease in the number of rearings following MK-801 treatment $[F(1,27)=3.36, p=.078]$. No significant differences with respect to the number of sections traversed were revealed among the groups.

\subsection{Forced swim}

The mean immobility times in the last five min of the test are shown in Fig. 5.

Neonatal MK-801 treatment significantly reduced immobility $[F(1,27)=9.93, p<.01]$.

Conversely, immobility was significantly increased by stress $[F(1,27)=14.87, p<.01]$.

Since the neonatal treatment $\times$ stress interaction was also significant $[F(1,27)=6.88, p$ $<.05]$, the simple main effects were tested. In SAL-treated rats, but not those treated with MK-801, chronic stress significantly increased immobility $[F(1,27)=21.74, p$ $<.01$ ], while MK-801 treatment significantly inhibited the potentiating effect of chronic stress on immobility $[F(1,27)=17.26, p<.01]$, although the drug had no effect in absence of this stress.

4. Discussion

The present study has demonstrated that repeated neonatal MK-801 treatment reduces immobility in the forced-swim test, and rearing activity in the open-field test. In particular, this treatment inhibited the potentiating effect of chronic stress on immobility 
in the forced-swim test. These results suggest that chronic neonatal NMDA receptor antagonism persistently affects cognitive or behavioral functions, and influences the effects of stress on these functions. Since the four behavioral tests were carried out in the same order, the sequence of testing could have affected the results of this study. However, as the tests here are not considered to be especially stressful for rats-with exception of the forced-swim test that was conducted at the end of the testing-, such effects may be small even if this is the case.

The most important result in the present study is that MK-801-treated rats showed markedly less immobility in the forced-swim test than those treated with SAL, when repeated forced-swim stress had been previously applied. To the best of my knowledge, this is the first study showing that neonatal NMDA receptor antagonism reduces immobility in the forced-swim test. This result suggests that SAL-treated rats can acquire an optimal coping strategy to conserve energy but rats treated with MK-801 cannot. Thus, this finding strongly suggests that neonatal MK-801 treatment alters stress coping or adaptation abilities.

This result also suggests that MK-801-treated rats are sensitive or vulnerable to stress. Since stress is a major second hit factor, this is consistent with the two-hit hypothesis which assumes that genetic or early developmental first hit factors may induce vulnerability to later second hit factors in adolescence or adulthood (Bayer et al., 1999; Feigenson et al., 2014; Maynard et al., 2001). Consequently, neonatal NMDA receptor antagonism may act as a first hit factor, conferring vulnerability to second hit factors. According to the two-hit hypothesis, animal models where the subject has been exposed to both first and second hit factors may be of value. In this regard, a previous study has shown that neonatal MK-801 treatment produces more robust behavioral or 
cognitive alterations when combined with isolation rearing stress (Lim et al., 2012). It suggests that two-hit models have greater validity and application as animal models of schizophrenia than those based on a first hit factor only, such as animals subjected to neonatal MK-801 treatment alone.

Other possibilities apart from stress-coping or adaptation disabilities could explain the decreased immobility in the forced-swim test seen in MK-801-treated rats. Firstly, MK-801 treatment could increase general sensitivity to outer stimuli. This is supported by the authors' observation that MK-801-treated rats were hypersensitive to external stimuli, which typically manifested as jumping or squealing upon being touched (Kawabe and Miyamoto, 2008). Secondly, neonatal MK-801 treatment could simply increase locomotor activity. However, contrary to this hypothesis, this treatment did not increase general activity, and even reduced the number of rearings, in the open-field test of the present study. Thirdly, it is possible that MK-801-treated rats are less depressive, since immobility in the forced-swim test is frequently used as an indicator of depression or lower motivation. According to this view, reduced immobility in MK-801-treated rats may reflect a higher resistance to stress. However, it appears that rodents in a forcedswim situation show active coping styles in the earlier stage, for example, struggling, jumping or swimming in the water; then switch to a passive coping strategy to conserve energy, for example, immobile or floating behavior (de Kloet and Molendijk, 2016). It seems, therefore, that passive coping styles are more adaptive than active ones. In particular, as the rats in the chronic stress groups had fully experienced the forced-swim situation, it is likely that the observed immobility reflects coping or adaptation ability rather than depression or lower motivation. At any rate, further studies using a different procedure are required to measure stress coping or depression in rats subjected to 
neonatal NMDA receptor antagonism and chronic stress.

Alternatively, less immobility in MK-801-treated rats could be attributed to memory problems. Since subjects had sufficient opportunity to acquire an optimal coping strategy during repeated exposure to the forced-swim paradigm, it is possible that MK-801-treated rats had memory deficits related to the stressful situation. This type of memory includes episodic or contextual memory, for which normal hippocampal function is needed (for example, Phillips and LeDoux, 1992). In fact, previous studies have indicated that chronic neonatal treatment with NMDA receptor antagonists produces memory deficits which may be attributed to hippocampal dysfunction (Gorter and de Bruin, 1992; Kawabe et al., 2007; Kawabe and Miyamoto, 2008; Sircar, 2003). However, memory problems alone cannot explain reduced immobility in MK-801treated rats, considering that these subjects tended to be less immobile even if they had not experienced the stressful situation previously.

It has been reported that neurons in the hippocampus (Conrad et al., 1999; Watanabe et al., 1992; Wood et al., 2004; Woolley et al., 1990) and the prefrontal cortex (Hains et al., 2009; Radley et al., 2004) are degenerated by stress or corticosterone, one of the principal adrenal glucocorticoids secreted by rodents in response to stress. These areas are known to be rich in glucocorticoid receptors, and it is believed that negative feedback is relayed from these regions to the hypothalamicpituitary-adrenal (HPA) axis via glucocorticoid receptors (Akana et al., 2001; Diorio et al., 1993; Herman et al., 1989; Sapolsky et al., 1984). Since it has been suggested that neonatal NMDA receptor blockade induces upregulation of NMDA receptors in the hippocampus and the frontal cortex (Sircar, 2003), and that stress or corticosterone treatment enhances glutamate release in these areas (Hascup et al., 2010; Lowy et al., 
1993; Moghaddam, 1993; Venero and Borrell, 1999), they may be more vulnerable to excitotoxicity based on excessive glutamatergic transmission due to stress exposure in MK-801-treated animals. Neural degeneration of these areas induced in this manner could bring about disinhibition or hyperactivation of the HPA axis, which may then act as a possible stress-vulnerability factor in these animals. In addition, the prefrontal cortex is reciprocally connected with the limbic system including the hippocampus and the amygdala, and generally thought to utilize information from these areas for appropriate decision-making. Therefore, irregular stress coping in MK-801-treated rats could be a consequence of abnormal decision-making based on prefrontal dysfunction. In this regard, it has been reported that neonatal MK-801 treatment impairs cognitive functions which are related to prefrontal performance such as cognitive flexibility (Stefani and Moghaddam, 2005) and working memory (Kawabe et al., 2007; Kawabe and Miyamoto, 2008; Stefani and Moghaddam, 2005).

In the open-field test, there was a trend toward decreased rearing activity following MK-801 treatment, in accordance with previous studies (Kawabe et al., 2007; Uehara et al., 2009). This may be related to the trend toward a decreased number of total choices in the present SA test induced by MK-801, suggesting that MK-801 treatment reduces locomotor activity. In addition, since illumination in the present open-field study was brighter than that in a typical living environment, the testing situation could have been more stressful or anxiety-inducing for the experimental subjects. Thus, lower activity in MK-801-treated rats might reflect increased stress or anxiety. On the other hand, the present study has also shown that chronic stress increases the number of rearings in the open-field test. This result is similar to some previous reports showing that chronic stress enhances locomotor activity (Grønli et al., 2005; Mineur et al., 2006), although 
other studies have reported a reduction in activity (Conrad et al., 1999; Taliaz et al., 2011; Wood et al., 2004). Open-field activity may be interpreted ambiguously, possibly indicating excitation or sedation, anxiety, novelty seeking or exploration, and so on. Furthermore, many environmental factors, including the lighting, the size of the arena, and the familiarity or novelty of the testing set-up, may affect the results of an openfield test. It should also be noted that horizontal activity, or the number of traversed sections, was not affected in this study by either MK-801 treatment or chronic stress. Therefore, other behavioral tests measuring emotionality or anxiety will be necessary to elucidate the nature of the decreasing trend seen with MK-801 treatment and augmentative effect of stress on rearing activity in this study.

Since working memory is profoundly impaired in schizophrenic patients (Goldman-Rakic, 1994; Manoach, 2003), this is often examined in animal models of schizophrenia. Indeed, working memory deficits are shown in such models (Enomoto and Floresco, 2009; Kawabe et al., 2007; Kawabe and Miyamoto, 2008; Lipska et al., 2002; Stefani and Moghaddam, 2005), including animals that have received neonatal treatment with NMDA receptor antagonists. Our previous studies showed that the same dose $(0.2 \mathrm{mg} / \mathrm{kg})$ and schedule (PND 7-20, twice daily) of neonatal MK-801 treatment as in the present study impaired working memory in the radial-arm maze (Kawabe et al., 2007) and the DNMTP (Kawabe and Miyamoto, 2008) tasks. However, the present study failed to show that this MK-801 treatment protocol impaired working memory in the SA test, even if the rats had undergone a chronic stress procedure. This discrepancy may be caused by the task characteristics, or whether external rewards are needed or not. Since the SA test does not require external rewards, it is essentially different from reward-motivated tasks including the radial-arm maze and the DNMTP tasks. 
390 Considering previous reports showing that animals that have received neonatal treatment with NMDA receptor antagonists are behaviorally sensitive to direct and indirect dopamine receptor agonists in adolescence or adulthood (Beninger et al., 2002; Dall'Olio et al., 1994; Uehara et al., 2010), neonatal NMDA receptor antagonism may induce hyperactivity of the dopaminergic system which is involved in reward-related behaviors. In this regard, it has been reported that neonatal NMDA receptor antagonism increases dopamine $\mathrm{D}_{2}$ receptor binding in the nucleus accumbens, which is a major component of the reward system (Dall'Olio et al., 1994). More simply, it is also possible that the SA test is less sensitive to working memory deficits than the DNMTP and the radial-arm maze tasks. However, irrespective of the underlying reason for the differences, it would be worthwhile to assess the stress-vulnerability of MK-801-treated rats using an alternative working memory test.

As severe impairments in PPI are associated with schizophrenia, it is valuable to measure this parameter in animal models of the disorder. Although some studies show that neonatal NMDA receptor antagonism impairs PPI (Uehara et al., 2009; Uehara et al., 2010; Wang et al., 2003; Wedzony et al., 2008), the present study does not demonstrate such an effect in MK-801-treated rats, even after the application of chronic stress. However, since even SAL-treated rats showed comparatively low PPI values in this study, floor effects may have masked the impact of the drug and stress. In the PPI test, one of the critical factors is the difference between the sound intensity of prepulse stimuli and that of background noise. Related to this, many studies show that the higher the intensity difference, the greater PPI (for example, Beninger et al., 2002; Lim et al., 2012; Ralph et al., 1999). Thus, in the present study, a lower intensity difference may have contributed to the lack of PPI impairment by NMDA receptor antagonism and 
stress. An experimental set-up using a higher prepulse intensity would be necessary to achieve robust PPI values and better sensitivity to experimental effects.

In the present study, chronic stress loading started from PND 56, and behavioral testing was conducted from PND 82. It is likely that the neonatal MK-801 treatment was still effective in the testing period here, considering our previous studies show that the same treatment severely impairs working memory in the radial-arm maze and the DNMTP tasks at almost the same ages (11 weeks old and above) as those in the present study (Kawabe et al., 2007; Kawabe and Miyamoto, 2008). However, unlike the measures used in those previous studies, it may be the case that this treatment is no longer effective with respect to the measures used in this particular study. In addition, it is also possible that MK-801-treated rats have critical developmental periods where stress or some second hit factors can affect these behavioral measures. Therefore, application of stress and/or behavioral testing during younger periods, such as puberty or adolescence, could reveal more profound effects of MK-801 treatment and/or stress.

In summary, the present study has shown that MK-801-treated rats may have a reduced ability to habituate or adapt to a stressful context. Although the present study supports the hypothesis that rats subjected to repeated neonatal treatment with NMDA receptor antagonists are sensitive or vulnerable to stress, additional studies are required to further test this hypothesis.

\section{Acknowledgments}

The author would like to thank Mrs. Maho Kitaguchi for her experimental assistance, and Enago (www.enago.jp) for the English language review. This research 
438 was supported in part by JSPS KAKENHI (grant numbers: 20530664, 23530959, $43926590180)$.

440

441 


\section{REFERENCES}

Abraham, W.C., Mason, S.E., 1988. Effects of the NMDA receptor/channel antagonists CPP and MK801 on hippocampal field potentials and long-term potentiation in anesthetized rats. Brain Research. 462, 40-46. http://doi.org/10.1016/00068993(88)90582-3.

Akana, S.F., Chu, A., Soriano, L., Dallman, M.F., 2001. Corticosterone exerts sitespecific and state-dependent effects in prefrontal cortex and amygdala on regulation of adrenocorticotropic hormone, insulin and fat depots. Journal of Neuroendocrinology. 13, 625-637. $\quad$ http://doi.org/10.1046/j.1365$\underline{2826.2001 .00676 . x}$.

Anisman, H., Hayley, S., Kelly, O., Borowski, T., Merali, Z., 2001. Psychogenic, neurogenic, and systemic stressor effects on plasma corticosterone and behavior: mouse strain-dependent outcomes. Behavioral Neuroscience. 115, 443-454.

Bayer, T.A., Falkai, P., Maier, W., 1999. Genetic and non-genetic vulnerability factors in schizophrenia: the basis of the "Two hit hypothesis". Journal of Psychiatric Research. 33, 543-548. http://doi.org/10.1016/S0022-3956(99)00039-4.

Beninger, R.J., Jhamandas, A., Aujla, H., Xue, I., Dagnone, R.V., Boegman, R.J., Jhamandas, K., 2002. Neonatal exposure to the glutamate receptor antagonist MK-801: Effects on locomotor activity and pre-pulse inhibition before and after sexual maturity in rats. Neurotoxicity Research. 4, 477-488. http://doi.org/10.1080/10298420290031414.

Bubeníková-Valešová, V., Horáček, J., Vrajová, M., Höschl, C., 2008. Models of schizophrenia in humans and animals based on inhibition of NMDA receptors. 
Neuroscience \& Biobehavioral Reviews. $32, \quad$ 1014-23. http://doi.org/10.1016/j.neubiorev.2008.03.012.

Conrad, C.D., Magariños, A.M., LeDoux, J.E., McEwen, B.S., 1999. Repeated restraint stress facilitates fear conditioning independently of causing hippocampal CA3 dendritic atrophy. Behavioral Neuroscience. 113, 902-913. http://doi.org/10.1037/0735-7044.113.5.902.

Dall'Olio, R., Facchinetti, F., Contestabile, A., Gandolfi, O., 1994. Chronic neonatal blockade of $N$-methyl-D-aspartate receptor by CGP 39551 increases dopaminergic function in adult rat. Neuroscience. 63, 451-455. http://doi.org/10.1016/0306-4522(94)90542-8.

de Kloet, E.R., Molendijk, M.L., 2016. Coping with the forced swim stressor: towards understanding an adaptive mechanism. Neural Plasticity. 2016, 6503162. http://doi.org/10.1155/2016/6503162.

Diorio, D., Viau, V., Meaney, M.J., 1993. The role of the medial prefrontal cortex (cingulate gyrus) in the regulation of hypothalamic-pituitary-adrenal responses to stress. Journal of Neuroscience. 13, 3839-3847.

Enomoto, T., Floresco, S.B., 2009. Disruptions in spatial working memory, but not short-term memory, induced by repeated ketamine exposure. Progress in NeuroPsychopharmacology and Biological Psychiatry. 33, 668-675. http://doi.org/10.1016/j.pnpbp.2009.03.013.

Facchinetti, F., Ciani, E., Dall'Olio, R., Virgili, M., Contestabile, A., Fonnum, F., 1993. Structural, neurochemical and behavioural consequences of neonatal blockade of NMDA receptor through chronic treatment with CGP 39551 or MK-801. Developmental Brain Research. 74, 219-224. http://doi.org/10.1016/0165- 
3806(93)90007-W.

Facchinetti, F., Dall'Olio, R., Ciani, E., Sparapani, M., Virgili, M., Contestabile, A., 1994. Long-lasting effects of chronic neonatal blockade of $N$-methyl-D-aspartate receptor through the competitive antagonist CGP 39551 in rats. Neuroscience. 60, 343-353. http://doi.org/10.1016/0306-4522(94)90248-8.

Feigenson, K.A., Kusnecov, A.W., Silverstein, S.M., 2014. Inflammation and the twohit hypothesis of schizophrenia. Neuroscience \& Biobehavioral Reviews. 38, 7293. http://doi.org/dx.doi.org/10.1016/j.neubiorev.2013.11.006.

Goldman-Rakic, P.S., 1994. Working memory dysfunction in schizophrenia. Journal of Neuropsychiatry \& Clinical Neurosciences. 6, 348-357. http://doi.org/10.1176/jnp.6.4.348.

Gorter, J.A., Botterblom, M.H.A., Feenstra, M.G.P., Boer, G.J., 1992a. Chronic neonatal NMDA receptor blockade with MK-801 alters monoamine metabolism in the adult rat. Neuroscience Letters. 137, 97-100. http://doi.org/10.1016/03043940(92)90307-S.

Gorter, J.A., de Bruin, J.P., 1992. Chronic neonatal MK-801 treatment results in an impairment of spatial learning in the adult rat. Brain Research. 580, 12-17. http://doi.org/10.1016/0006-8993(92)90921-U.

Gorter, J.A., Titulaer, M., Bos, N.P.A., Huisman, E., 1991. Chronic neonatal MK-801 administration leads to a long-lasting increase in seizure sensitivity during the early stages of hippocampal kindling. Neuroscience Letters. 134, 29-32. http://doi.org/10.1016/0304-3940(91)90501-J.

Gorter, J.A., Veerman, M., Mirmiran, M., 1992b. Hippocampal neuronal responsiveness to NMDA agonists and antagonists in the adult rat neonatally treated with MK- 

N.

Grønli, J., Murison, R., Fiske, E., Bjorvatn, B., Sørensen, E., Portas, C.M., Ursin, R., 2005. Effects of chronic mild stress on sexual behavior, locomotor activity and consumption of sucrose and saccharine solutions. Physiology \& Behavior. 84, 571-577. http://doi.org/10.1016/j.physbeh.2005.02.007.

Hains, A.B., Vu, M.A., Maciejewski, P.K., van Dyck, C.H., Gottron, M., Arnsten, A.F., 2009. Inhibition of protein kinase $\mathrm{C}$ signaling protects prefrontal cortex dendritic spines and cognition from the effects of chronic stress. Proceedings of the National Academy of Sciences of the United States of America. 106, 1795717962. http://doi.org/10.1073/pnas.0908563106.

Harris, E.W., Ganong, A.H., Cotman, C.W., 1984. Long-term potentiation in the hippocampus involves activation of N-methyl-D-aspartate receptors. Brain Research. 323, 132-137. http://doi.org/10.1016/0006-8993(84)90275-0.

Hascup, E.R., Hascup, K.N., Stephens, M., Pomerleau, F., Huettl, P., Gratton, A., Gerhardt, G.A., 2010. Rapid microelectrode measurements and the origin and regulation of extracellular glutamate in rat prefrontal cortex. Journal of Neurochemistry. 115, 1608-1620. http://doi.org/10.1111/j.1471$\underline{4159.2010 .07066 . x}$.

Herman, J.P., Schafer, M.K., Young, E.A., Thompson, R., Douglass, J., Akil, H., Watson, S.J., 1989. Evidence for hippocampal regulation of neuroendocrine neurons of the hypothalamo-pituitary-adrenocortical axis. Journal of Neuroscience. 9, 3072-3082.

Ikonomidou, C., Bosch, F., Miksa, M., Bittigau, P., Vöckler, J., Dikranian, K., Tenkova, 

and apoptotic neurodegeneration in the developing brain. Science. 283, 70-74. http://doi.org/10.1126/science.283.5398.70.

541

Javitt, D.C., Zukin, S.R., 1991. Recent advances in the phencyclidine model of schizophrenia. American Journal of Psychiatry. 148, 1301-1308. http://doi.org/10.1176/ajp.148.10.1301.

Kawabe, K., Ichitani, Y., Iwasaki, T., 1998a. Effects of intrahippocampal AP5 treatment on radial-arm maze performance in rats. Brain Research. 781, 300-306. http://doi.org/10.1016/S0006-8993(97)01256-0.

Kawabe, K., Iwasaki, T., Ichitani, Y., 2007. Repeated treatment with N-methyl-Daspartate antagonists in neonatal, but not adult, rats causes long-term deficits of radial-arm maze learning. Brain Research. 1169, 77-86. http://doi.org/10.1016/j.brainres.2007.06.062.

Kawabe, K., Miyamoto, E., 2008. Effects of neonatal repeated MK-801 treatment on delayed nonmatching-to-position responses in rats. Neuroreport. 19, 969-973. http://doi.org/10.1097/WNR.0b013e328302ee31.

Kawabe, K., Yoshihara, T., Ichitani, Y., Iwasaki, T., 1998b. Intrahippocampal Dcycloserine improves MK-801-induced memory deficits: radial-arm maze performance in rats. Brain Research. 814, 226-230. http://doi.org/10.1016/S0006-8993(98)01043-9.

Lewis, D.A., Levitt, P., 2002. Schizophrenia as a disorder of neurodevelopment. Annual Review of $\quad$ Neuroscience. $\quad 25, \quad 409-432$. http://doi.org/10.1146/annurev.neuro.25.112701.142754.

Lim, A.L., Taylor, D.A., Malone, D.T., 2012. A two-hit model: behavioural 
investigation of the effect of combined neonatal MK-801 administration and isolation rearing in the rat. Journal of Psychopharmacology. 26, 1252-1264. http://doi.org/10.1177/0269881111430751.

Lipska, B.K., Aultman, J.M., Verma, A., Weinberger, D.R., Moghaddam, B., 2002. Neonatal damage of the ventral hippocampus impairs working memory in the rat. Neuropsychopharmacology. 27, 47-54. http://doi.org/10.1016/S0893$\underline{133 X(02) 00282-8}$.

Lowy, M.T., Gault, L., Yamamoto, B.K., 1993. Adrenalectomy attenuates stressinduced elevations in extracellular glutamate concentrations in the hippocampus. Journal of Neurochemistry. 61, 1957-1960. http://doi.org/10.1111/j.14714159.1993.tb09839.x.

Manoach, D.S., 2003. Prefrontal cortex dysfunction during working memory performance in schizophrenia: reconciling discrepant findings. Schizophrenia Research. 60, 285-298. http://doi.org/10.1016/S0920-9964(02)00294-3.

Maynard, T.M., Sikich, L., Lieberman, J.A., LaMantia, A.S., 2001. Neural development, cell-cell signaling, and the "two-hit" hypothesis of schizophrenia. $\begin{array}{lll}\text { Schizophrenia } \quad \text { Bulletin. } & \text { 27, }\end{array}$ 457-476. http://doi.org/10.1093/oxfordjournals.schbul.a006887.

Mineur, Y.S., Belzung, C., Crusio, W.E., 2006. Effects of unpredictable chronic mild stress on anxiety and depression-like behavior in mice. Behavioural Brain Research. 175, 43-50. http://doi.org/10.1016/j.bbr.2006.07.029.

Moghaddam, B., 1993. Stress preferentially increases extraneuronal levels of excitatory amino acids in the prefrontal cortex: comparison to hippocampus and basal ganglia. Journal of Neurochemistry. 60 , 1650-1657. 

http://doi.org/10.1111/j.1471-4159.1993.tb13387.x.

Morris, R.G.M., 1989. Synaptic plasticity and learning: selective impairment of learning rats and blockade of long-term potentiation in vivo by the $N$-methyl-D-aspartate receptor antagonist AP5. Journal of Neuroscience. 9, 3040-3057.

Morris, R.G.M., Anderson, E., Lynch, G.S., Baudry, M., 1986. Selective impairment of learning and blockade of long-term potentiation by an $N$-methyl-D-aspartate $\begin{array}{lllll}\text { receptor } & \text { antagonist, } & \text { AP5. } & \text { Nature. } & 319,776 .\end{array}$ http://doi.org/10.1038/319774a0.

Morris, R.G.M., Halliwell, R.F., Bowery, N., 1989. Synaptic plasticity and learning II: Do different kinds of plasticity underlie different kinds of learning? Neuropsychologia. 27, 41-59. http://doi.org/10.1016/0028-3932(89)90089-4.

Nakatani-Pawlak, A., Yamaguchi, K., Tatsumi, Y., Mizoguchi, H., Yoneda, Y., 2009. Neonatal phencyclidine treatment in mice induces behavioral, histological and neurochemical abnormalities in adulthood. Biological and Pharmaceutical Bulletin. 32, 1576-1583.

Niikura, R., Nozawa, T., Yamada, K., Kato, K., Ichitani, Y., 2015. Latent inhibition in rats neonatally treated chronically with MK-801: differential effects on conditioned taste aversion and conditioned emotional response. Behavioural Brain Research. 283, 102-107. http://doi.org/10.1016/j.bbr.2015.01.029.

O'Donoghue, D.L., Poff, C.R., Block, J.J., 1993. Chronic neonatal N-methyl-D-aspartate receptor antagonism with MK-801 increases the number of corticospinal cells retained into adulthood in the rat. Neuroscience Letters. 158, 143-146. http://doi.org/10.1016/0304-3940(93)90249-K.

Phillips, A.G., LeDoux, J.E., 1992. Differential contribution of amygdala and 
hippocampus to cued and contextual fear conditioning. Behavioral Neuroscience. 106, 274-285. http://doi.org/10.1037/0735-7044.106.2.274.

Radley, J.J., Sisti, H.M., Hao, J., Rocher, A.B., McCall, T., Hof, P.R., McEwen, B.S., Morrison, J.H., 2004. Chronic behavioral stress induces apical dendritic reorganization in pyramidal neurons of the medial prefrontal cortex. Neuroscience. 125, 1-6. http://doi.org/10.1016/j.neuroscience.2004.01.006.

Ralph, R.J., Varty, G.B., Kelly, M.A., Wang, Y.M., Caron, M.G., Rubinstein, M., Grandy, D.K., Low, M.J., Geyer, M.A., 1999. The dopamine $\mathrm{D}_{2}$, but not $\mathrm{D}_{3}$ or $\mathrm{D}_{4}$, receptor subtype is essential for the disruption of prepulse inhibition produced by amphetamine in mice. Journal of Neuroscience. 19, 4627-4633.

Sapolsky, R.M., Krey, L.C., McEwen, B.S., 1984. Glucocorticoid-sensitive hippocampal neurons are involved in terminating the adrenocortical stress response. Proceedings of the National Academy of Sciences of the United States of America. 81, 6174-6177.

Shishkina, G.T., Bulygina, V.V., Dygalo, N.N., 2015. Behavioral effects of glucocorticoids during the first exposures to the forced swim stress. Psychopharmacology (Berl). 232, 851-860. http://doi.org/10.1007/s00213-0143718-8.

Sircar, R., 2003. Postnatal phencyclidine-induced deficit in adult water maze performance is associated with $N$-methyl-D-aspartate receptor upregulation. International Journal of Developmental Neuroscience. 21, 159-167. http://doi.org/10.1016/S0736-5748(03)00026-1.

Stefani, M.R., Moghaddam, B., 2005. Transient N-methyl-D-aspartate receptor blockade in early development causes lasting cognitive deficits relevant to 
schizophrenia.

Biological

Psychiatry.

57,

433-436. http://doi.org/10.1016/j.biopsych.2004.11.031.

Taliaz, D., Loya, A., Gersner, R., Haramati, S., Chen, A., Zangen, A., 2011. Resilience to chronic stress is mediated by hippocampal brain-derived neurotrophic factor. Journal of Neuroscience.

31, $4475-4483$. http://doi.org/10.1523/JNEUROSCI.5725-10.2011.

Uehara, T., Sumiyoshi, T., Seo, T., Itoh, H., Matsuoka, T., Suzuki, M., Kurachi, M., 2009. Long-term effects of neonatal MK-801 treatment on prepulse inhibition in young adult rats. Psychopharmacology (Berl). 206, 623-630. http://doi.org/10.1007/s00213-009-1527-2.

Uehara, T., Sumiyoshi, T., Seo, T., Matsuoka, T., Itoh, H., Suzuki, M., Kurachi, M., 2010. Neonatal exposure to MK-801, an N-methyl-D-aspartate receptor antagonist, enhances methamphetamine-induced locomotion and disrupts sensorimotor gating in pre- and postpubertal rats. Brain Research. 1352, 223230. http://doi.org/10.1016/j.brainres.2010.07.013.

Venero, C., Borrell, J., 1999. Rapid glucocorticoid effects on excitatory amino acid levels in the hippocampus: a microdialysis study in freely moving rats. European Journal of Neuroscience. 11, 2465-2473. http://doi.org/10.1046/j.14609568.1999.00668.x.

Wang, C., Anastasio, N., Popov, V., Leday, A., Johnson, K.M., 2004. Blockade of Nmethyl-D-aspartate receptors by phencyclidine causes the loss of corticostriatal neurons.

Neuroscience.

125 ,

473-483. http://doi.org/10.1016/j.neuroscience.2004.02.003.

Wang, C., McInnis, J., West, J.B., Bao, J., Anastasio, N., Guidry, J.A., Ye, Y., 
Salvemini, D., Johnson, K.M., 2003. Blockade of phencyclidine-induced cortical apoptosis and deficits in prepulse inhibition by M40403, a superoxide dismutase mimetic. Journal of Pharmacology and Experimental Therapeutics. 304, 266-71. http://doi.org/10.1124/jpet.102.041798.

Watanabe, Y., Gould, E., McEwen, B.S., 1992. Stress induces atrophy of apical dendrites of hippocampal CA3 pyramidal neurons. Brain Research. 588, 341345.

Wedzony, K., Fijal, K., Mackowiak, M., Chocyk, A., Zajaczkowski, W., 2008. Impact of postnatal blockade of $\mathrm{N}$-methyl-D-aspartate receptors on rat behavior: a search for a new developmental model of schizophrenia. Neuroscience. 153, 13701379. http://doi.org/10.1016/j.neuroscience.2008.03.016.

Weinberger, D.R., 1987. Implications of normal brain development for the pathogenesis of schizophrenia. Archives of General Psychiatry. 44, 660-669. http://doi.org/10.1001/archpsyc.1987.01800190080012.

Wood, G.E., Young, L.T., Reagan, L.P., Chen, B., McEwen, B.S., 2004. Stress-induced structural remodeling in hippocampus: prevention by lithium treatment. Proceedings of the National Academy of Sciences of the United States of America. 101, 3973-3978. http://doi.org/10.1073/pnas.0400208101.

Woolley, C.S., Gould, E., McEwen, B.S., 1990. Exposure to excess glucocorticoids alters dendritic morphology of adult hippocampal pyramidal neurons. Brain Research. 531, 225-231. http://doi.org/10.1016/0006-8993(90)90778-A.

Yoshihara, T., Ichitani, Y., 2004. Hippocampal N-methyl-D-aspartate receptor-mediated encoding and retrieval processes in spatial working memory: delay-interposed radial maze performance in rats. Neuroscience. 129, 1-10. 
683

684 
685

686

687

688

689

690

691

692

693

694

695

696

697

698

Figure legends

Fig. 1. PPI scores (mean \pm SEM).

Fig. 2. Startle response amplitudes in the pulse-alone trials (A) and the prepulse trials (B) in the PPI test (mean \pm SEM).

Fig. 3. Percentage spontaneous alternations (\% SAs) (A) and the number of total choices (B) in the spontaneous alternation test (mean $\pm \mathrm{SEM}) . \dagger p<.1$.

Fig. 4. The number of sections traversed (A) and the number of rearings (B) in the open-field test (mean $\pm \mathrm{SEM}) .{ }^{*} p<.05, \dagger p<.1$.

Fig. 5. Immobility times in the last five min of the forced-swim test (mean $\pm \mathrm{SEM}){ }^{* *} p$ $<.01$. 
Fig. 1

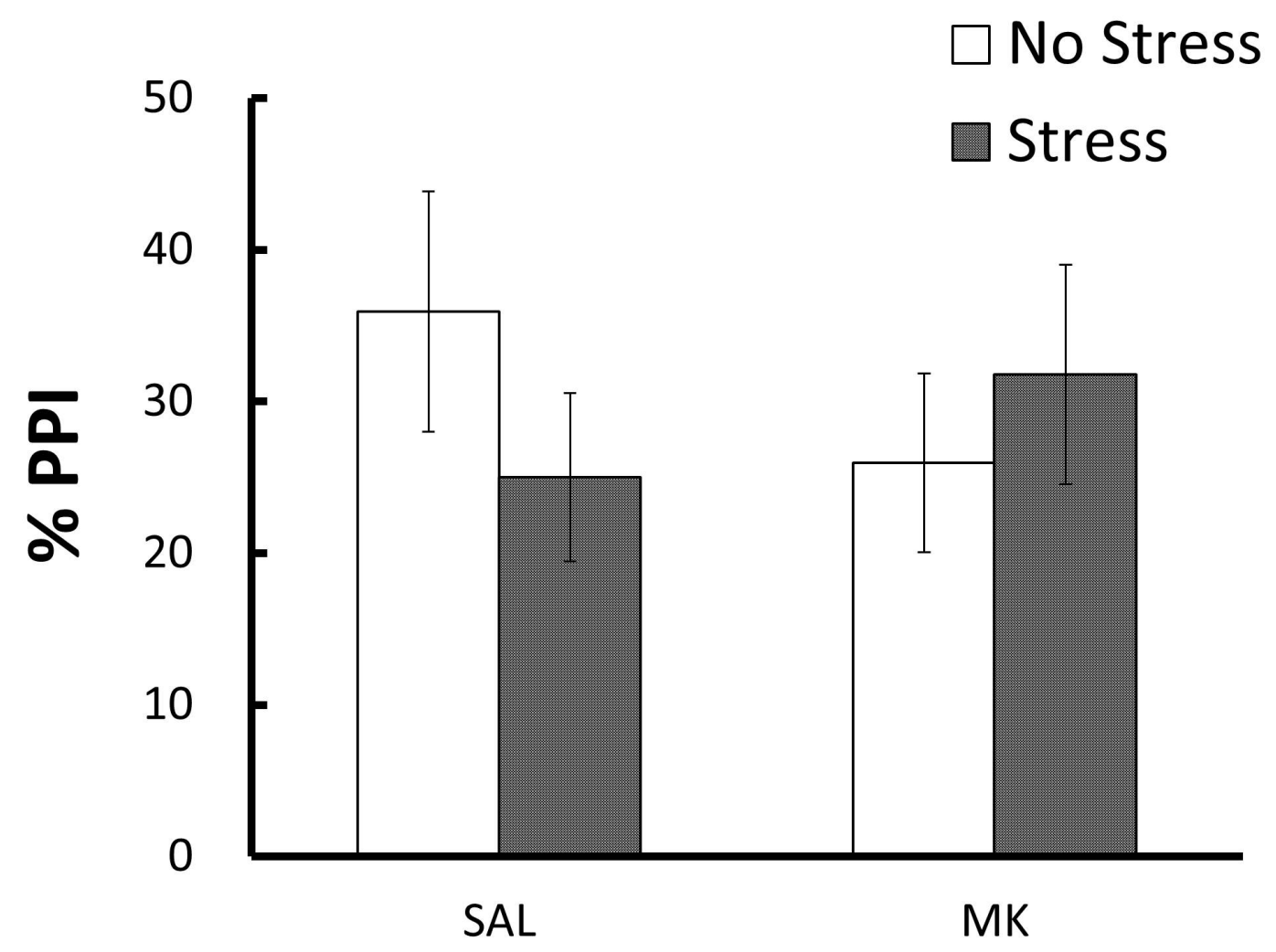


Fig. 2
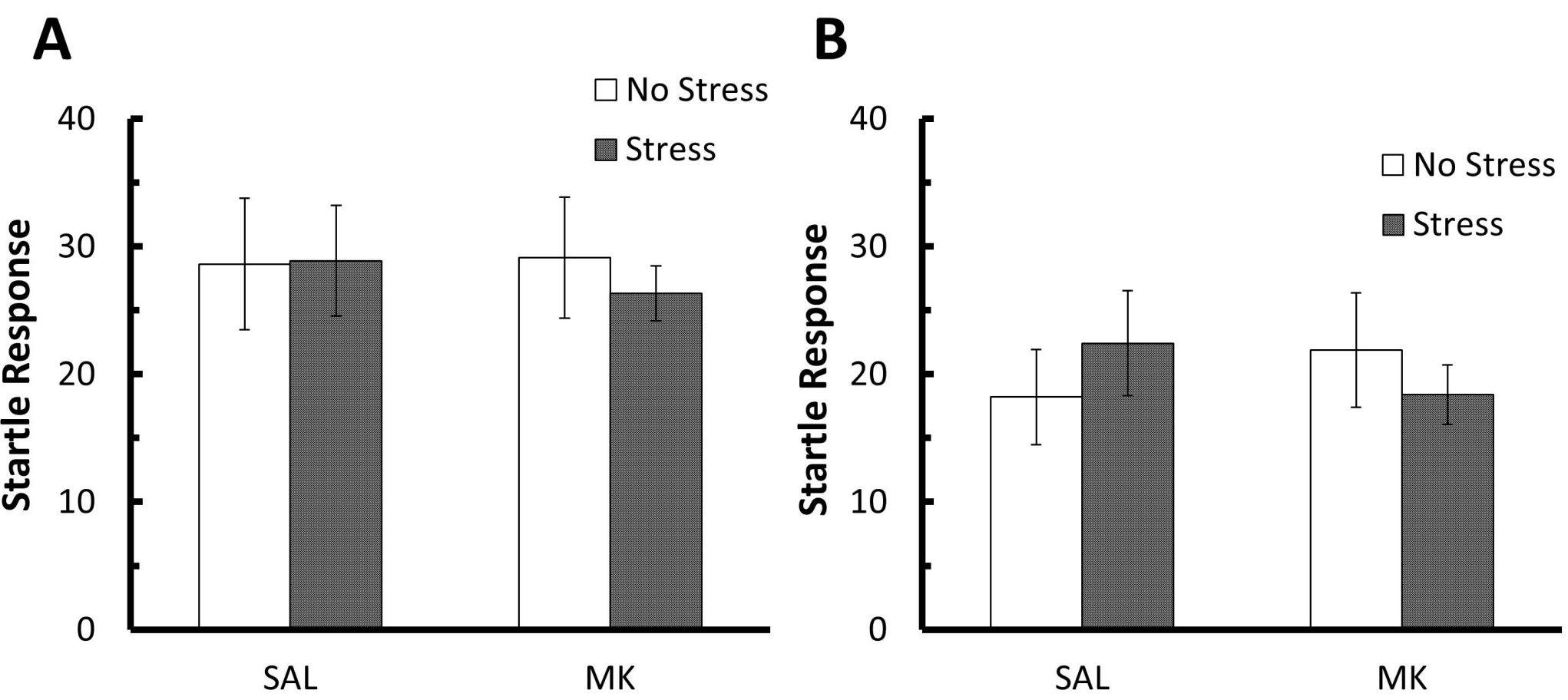
Fig. 3
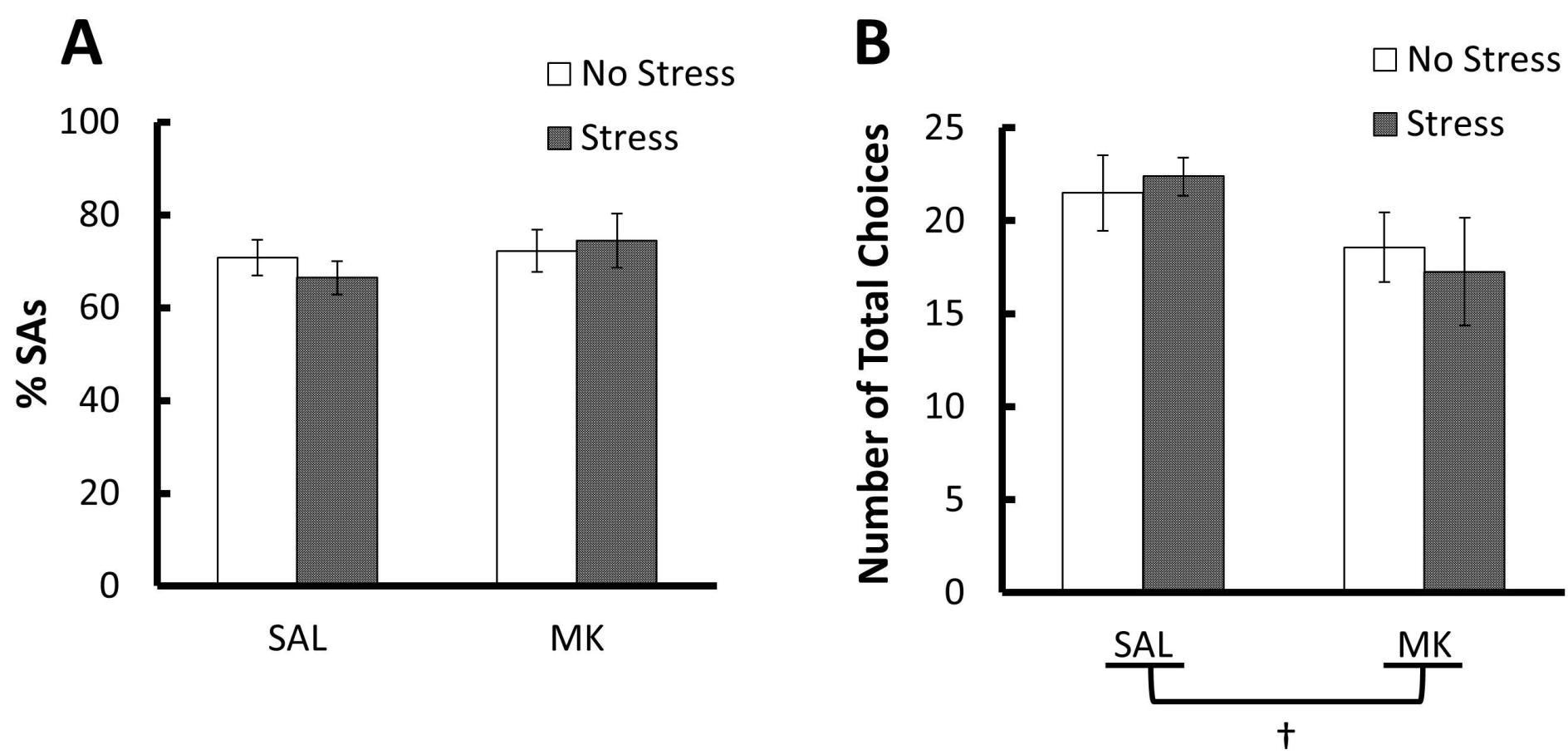
Fig. 4

A

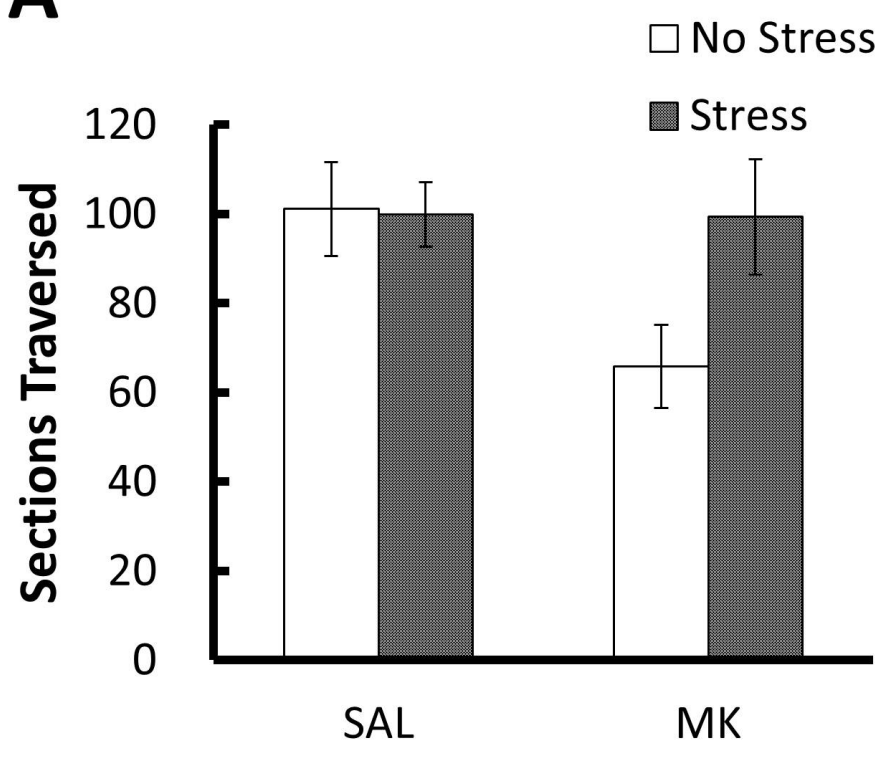

B

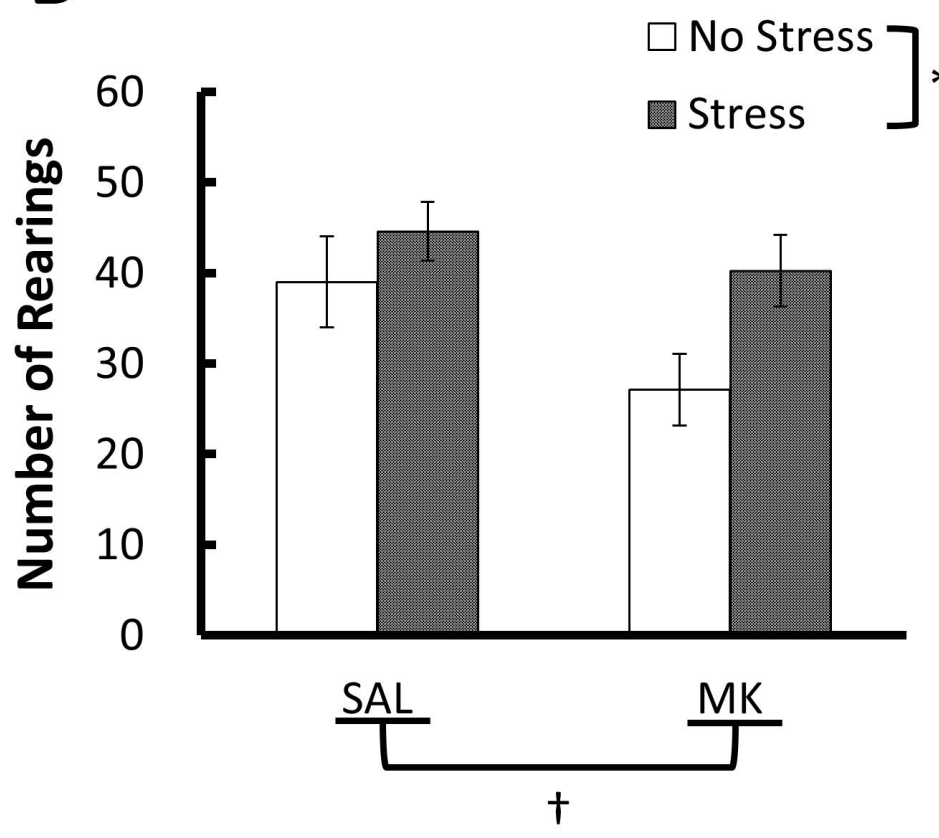


Fig. 5

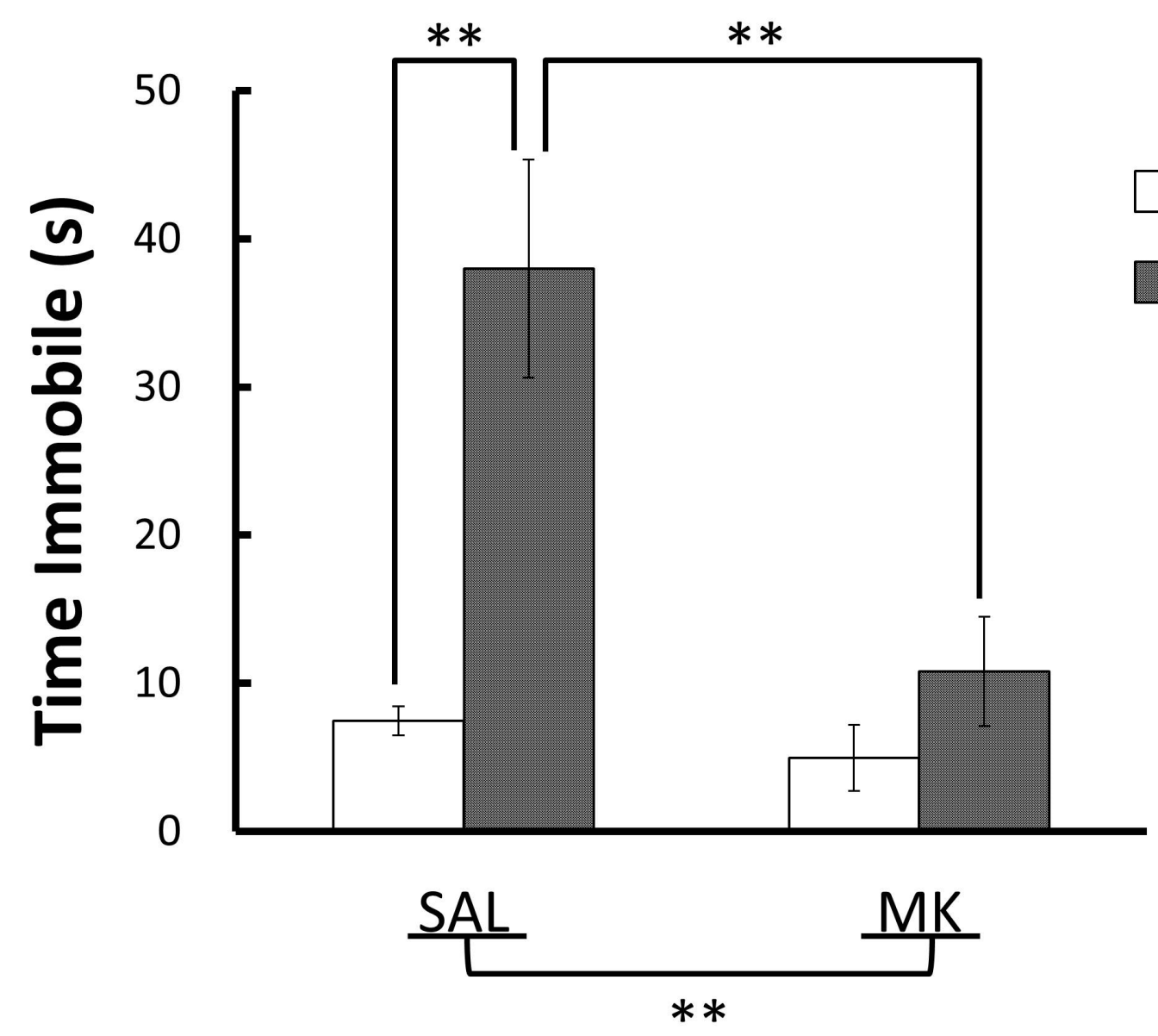

$\left.\begin{array}{l}\square \text { No Stress } \\ \square \text { Stress }\end{array}\right] * *$ 